\title{
Effects of carbohydrate combined with caffeine on repeated sprint cycling and agility performance in female athletes
}

\author{
Chia-Lun Lee ${ }^{1}$, Ching-Feng Cheng ${ }^{2 *}$, Todd A Astorino ${ }^{3}$, Chia-Jung Lee ${ }^{2}$, Hsin-Wei Huang $^{4}$ and Wen-Dien Chang ${ }^{5}$
}

\begin{abstract}
Background: Caffeine (CAF) has been shown to improve performance during early phase of repeated sprint exercise; however some studies show that CAF also increases the magnitude of physical stress represented by augmented blood lactate, glucose, and cortisol concentrations during latter phase of repeated sprint exercise. No studies have investigated the efficacy of combined carbohydrate $(\mathrm{CHO})$ and $\mathrm{CAF}$ consumption during repeated sprint exercise (RSE) in female athletes. Thus, the purpose of this study was to investigate the effects of CAF with CHO supplementation on RSE and agility.
\end{abstract}

Methods: Eleven female athletes completed four experimental trials performed $7 \mathrm{~d}$ apart in a double-blind, randomized, and counter-balanced crossover design. Treatments included CAF + PLA (placebo), CAF + CHO, PLA + CHO, and PLA + PLA. Participants ingested capsules containing $6 \mathrm{mg} \cdot \mathrm{kg}^{-1}$ of CAF or PLA 60 -min prior to RSE, and $0.8 \mathrm{~g} \cdot \mathrm{kg}^{-1}$ of $\mathrm{CHO}$ solution or PLA immediately before the RSE, which consisted of ten sets of $5 \times 4$-s sprints on the cycle ergometer with 20-s active recovery. The agility T-test (AT-test) was performed before and after the RSE. Blood samples were acquired to assess glucose, lactate, testosterone, and cortisol.

Results: During Set 6 of RSE, peak power and mean power were significantly higher in PLA + CHO than those in CAF + PLA and PLA + PLA, respectively $(p<.05)$. Total work was significantly increased by $4.8 \%$ and $5.9 \%$ with PLA + CHO than those of $\mathrm{CAF}+\mathrm{CHO}$ and $\mathrm{CAF}+\mathrm{PLA}$ during Set 3. PLA + CHO also increased total work more than CAF + PLA and PLA + PLA did during Set $6(p<.05)$. No significant differences in AT-test performance either before or after the RSE were occurred among treatments $(p>.05)$. Blood lactate and glucose concentrations were significantly higher under $\mathrm{CAF}+\mathrm{CHO}, \mathrm{CAF}+\mathrm{PLA}$, and PLA $+\mathrm{CHO}$ versus PLA + PLA $(p<.05)$, but no differences in testosterone or cortisol levels were found $(p>05)$.

Conclusions: Findings indicate that $\mathrm{CAF}+\mathrm{PLA}$ or $\mathrm{CAF}+\mathrm{CHO}$ ingestion did not improve repeated sprint performance with short rest intervals or agility. However, $\mathrm{CHO}$ ingested immediately prior to exercise provided a small but significant benefit on RSE performance in female athletes.

Keywords: Anaerobic capacity, Ergogenic aids, Fatigue, Hormone, Metabolic substrate, Nutrition

\section{Background}

Most team sports include performance of moderate- to long duration exercise interspersed with repeated bouts of high-intensity activities as well as periods of low-tomoderate active recovery or passive rest. The work: rest ratio of the team sport athlete is around 1:4.5 [1], and

\footnotetext{
* Correspondence: andescheng@ntnu.edu.tw

${ }^{2}$ Department of Athletic Performance, National Taiwan Normal University, Taipei, Taiwan

Full list of author information is available at the end of the article
}

average number of sprints completed during competition is approximately 20-60 times with an approximate sprint duration equal to $2-4-\mathrm{s}$ [2]. Girard et al. [3] reported that intermittent sprint exercise (ISE) differs greatly from repeated sprint exercise (RSE), that is, ISE is characterized by short-duration sprints $(\leq 10-s)$ interspersed with long recovery periods (60-300-s); however, RSE is characterized by similar exercise duration $(\leq 10-s)$ interspersed with insufficient recovery ( $\leq 60-s)$. Gaitanos et al. [4] indicated that the inadequate recovery inherent in RSE 
(6-s maximal sprints with 30-s rest intervals) may impair sprint performance because of limited adenosine triphosphate (ATP) supply from anaerobic metabolism (glycolysis and phosphocreatine $(\mathrm{PCr})$ resynthesis) during the transient recovery between sprints, and increased acidosis. Thus, the strategies of nutritional ingestion are needed to preserve repeated sprint performance in competitive athletes.

It is common practice for team sport athletes to consume carbohydrate $(\mathrm{CHO})$ to improve intermittent exercise capacity $[5,6]$ and endurance performance $[7,8]$, which is thought to occur via central nervous system (CNS) activation and other potential mechanisms such as higher rates of $\mathrm{CHO}$ oxidation $[9,10]$. Another ergogenic aid that has routinely been used by athletes is caffeine (CAF) [11]. Existing data show that CAF supplementation may benefit sprint performance $[12,13]$ and reactive agility performance [14] via various mechanisms [15]. However, one study demonstrated that caffeine was ergolytic for mean power and fatigue index during the high-intensity sprint test when a $24 \times 4$-s cycling sprint test with 20 -s of active recovery was completed versus a 90 -s active recovery between each sprint bout [16]. Numerous studies have also reported that CAF ingestion has a small or negligible effect on sprint performance [16-18] when repeated sprint tests $(\leq 10-\mathrm{s})$ are interspersed with short rest periods ( $\leq 60-\mathrm{s})$, as well as no effect on reactive agility [19]. Although CAF significantly improved ISE [12,13,20], a number of studies have suggested that CAF doses of 2-6 $\mathrm{mg} \cdot \mathrm{kg}^{-1}$ are likely to improve ISE but not RSE performance; in other words, caffeine ingestion may negatively affect repeated sprint performance with short recovery intervals in the later stages of exercise [16,21]. If $\mathrm{CHO}$ plus $\mathrm{CAF}$ could potentiate benefits of $\mathrm{CHO}$ on substrate metabolism and improve CNS modulation, then CAF may enhance RSE performance. Some studies have examined changes in metabolism when CAF is coingested with CHO. For example, Yeo et al. [22] found that coingestion of $\mathrm{CHO}$ with $\mathrm{CAF}$ promoted intestinal glucose absorption resulting in greater exogenous $\mathrm{CHO}$ oxidation than $\mathrm{CHO}$ ingestion alone. In addition, intestinal glucose absorption was significantly increased with carbohydrate-electrolyte plus CAF compared with a carbohydrate-electrolyte solution alone [23]. Several studies show that combined intake of $\mathrm{CHO}$ and CAF may be ergogenic for intermittent sprint performance later in exercise [24-27] and lower rating of perceived exertion (RPE) and fatigue index [28]. However, certain studies have reported that ingesting $\mathrm{CHO}$ with $\mathrm{CAF}$ does not affect time-trial performance $[23,29,30]$. Thus, further studies are needed to clarify the effects of $\mathrm{CHO}$ and CAF coingestion on RSE performance.

Team sports require many skills other than running in a straight line, including brief pauses, cutting actions, and rapid direction and speed changes, which all are important elements of agility. The consequences of studies focused on the improvements of agility performance after ingesting $\mathrm{CAF}$ and/or $\mathrm{CHO}$ remain controversial. Duvnjak-Zaknich et al. [14] showed that ingesting CAF may benefit reactive agility in trained male athletes, but Lorino et al. [19] indicated that CAF does not improve proagility shuttle run performance in young adult males. Roberts et al. [25] investigated the combined effects of $\mathrm{CHO}$ and $\mathrm{CAF}$ on a sustained high-intensity test of speed and agility in male rugby players, indicating the agility performance was not significantly different between trials but the likelihood of $2 \%$ improvements for $\mathrm{CHO}+\mathrm{CAF}$ over placebo. In female soccer players, Red Bull containing low doses of CAF (80 mg; $1.3 \mathrm{mg} \cdot \mathrm{kg}^{-1}$ ) and $\mathrm{CHO}\left(27 \mathrm{~g} ; \sim 0.4 \mathrm{~g} \cdot \mathrm{kg}^{-1}\right)$ did not provide ergogenic effects on repeated agility T-test performance [31]. However, there are limited evidences investigating the effects of $\mathrm{CHO}$ and/or CAF with moderate dosage on agility performance in female athletes. It is unclear whether $\mathrm{CAF}$ or $\mathrm{CHO}+\mathrm{CAF}$ supplementation by female athletes, especially in team sports, enhances agility in change of direction (e.g. agility T-test) and in fatigued condition (e.g. after a long-time repeated sprint test rather than short-time). Thus, further studies should be conducted to clarify the effects of CAF and/or CHO supplementation on agility performance during various exercise stages.

Although no significant differences were found on salivary testosterone and cortisol concentrations after repeated bouts of supra-maximal exercise in female adolescents [32], ingestion of CAF with moderate dose might elevate the salivary cortisol concentrations [33], and the benefit of caffeine on performance might be counteracted by the increases in cortisol and the decreases in testosterone: cortisol ratio [34]. Walker et al. [35] reported that ingesting a placebo and CAF increased cortisol concentration more than ingesting only $\mathrm{CHO}$ after a 2-h endurance cycling exercise. $\mathrm{CHO}$ could offer some protection against the fall in testosterone: cortisol ratio during short-term intense exercise training [36]. It is likely that the effects of $\mathrm{CHO}$ on cortisol release regulation are larger than CAF, and may occur by activating the hypothalamic-pituitary-adrenal axis, providing a natural negative-feedback system through the coordination of cortisol, whereas no effect has been observed on hormonal and physiological responses after RSE [37]. However, it is unclear whether ingesting $\mathrm{CHO}$, or $\mathrm{CAF}$ and/or $\mathrm{CHO}$ causes RSE performance changes and hormonal reactions in women.

To date, no study examined the effect of ingestion of caffeine + placebo (CAF + PLA), caffeine + carbohydrate $(\mathrm{CAF}+\mathrm{CHO})$, carbohydrate + placebo $(\mathrm{CHO}+\mathrm{PLA})$, or placebo + placebo (PLA + PLA) on prolonged period of repeated sprint ability and agility performance for women in team sports. Therefore, the primary purpose of this study 
was to examine the effects of ingesting CAF combined with PLA, CAF + CHO, CHO + PLA, or PLA + PLA on repeated sprint performance tasks simulating team sports in female athletes. It is hypothesized that (1) CAF $+\mathrm{CHO}$ may improve repeated sprint performance and agility more than CAF + PLA and PLA + PLA do, and (2) $\mathrm{CAF}+\mathrm{PLA}$ or CAF + CHO may affect blood metabolism throughout repeated sprint exercise (RSE).

\section{Methods}

\section{Participants}

Eleven trained female athletes (age $=21.3 \pm 1.2 \mathrm{yr}$, height $=$ $164.2 \pm 5.7 \mathrm{~cm}$, and body mass $=58.6 \pm 7.3 \mathrm{~kg}$ ), members of Division I collegiate team-sport teams, volunteered to take part in this study. They reported habitual caffeine intake $=$ 50 to $100 \mathrm{mg} \cdot \mathrm{d}^{-1}$. All participants were regularly involved in team-sport competition such as basketball or volleyball and engaged in training $12.6 \pm 1.2$ hours/week. Participants were informed of the experimental procedures and potential risks before providing written informed consent. Prior to a familiarization session replicating the experimental procedure, all participants were screened for medical history and legal ergogenic aids use, and the results showed that none had taken any medicines (included prescription and over-the-counter medications) or ergogenic aids (which may influence multiple sprint performance, e.g., creatine) for at least 3 months prior to the experiment. A comprehensive list of dietary food products and medicines containing caffeine was provided to participants prior to the first familiarization trial. Participants abstained from all foods and liquids containing caffeine for 48-h before the experimental trials, as well as any alcohol and intense exercise for at least 24-h prior to all sessions. In addition, participants completed a questionnaire inquiring whether they experienced nausea, vomiting, muscle cramps, flatulence, diarrhea, anxiety, quivering, headaches, or other symptoms in order to evaluate any side effects experienced prior to exercise testing. The investigation was approved by the University Institutional Review Board.

\section{Experimental design}

Each participant visited the laboratory on five separate occasions. The first visit included preliminary testing to familiarize participants with the procedures and to minimize any learning effects. Once familiar with the protocol, each participant undertook four experimental trials separated by at least $7 \mathrm{~d}$. Treatment order was randomly assigned and counterbalanced using a Latin squares design, and was provided in a double-blind fashion, participants and researchers were blind to treatment assignment. After ingestion, the participants completed the agility T-test (AT-test) and RSE after a dynamic warm up. The AT-test used in this study was similar with a previous study that showed this test has a highly reliability and validity [38]. During exercise, heart rate (HR) was regularly assessed with a Polar heart rate monitor (Polar S810 ${ }^{\mathrm{m}}$, Polar Electro Inc, Finland) and the RPE was measured using a Borg 6-20 RPE scale [39]. Participants were familiarized with the RPE scale during the preliminary test. Blood samples were obtained throughout exercise (Figure 1).

\section{Treatment ingestion}

Participants completed four experimental trials: $\mathrm{CAF}+$ PLA, CAF + CHO, CHO + PLA, and PLA + PLA. Participants arrived at the laboratory according to the time sheet. Within subjects, the time of each trial remained consistent for all trials to avoid any influence of circadian variance. On arrival to the laboratory, participants were provided with a prepacked meal with an energy content of $492.75 \mathrm{Kcal}$, composed of $64 \%$ carbohydrate, $23 \%$ fat, and $13 \%$ protein. At 7:00 AM, after consuming their prepacked breakfast, participants ingested opaque gelatin capsules containing either $6 \mathrm{mg} \cdot \mathrm{kg}^{-1}$ of CAF (Sigma-Aldrich, Sydney, Australia) or an equal dosage of placebo (cellulose, Holy Food, Taoyuan, Taiwan), along with $200 \mathrm{ml}$ of water [16]. Participants then rested in a quiet room for 50-min prior to ingesting the carbohydrate solution drink or placebo. Before commencing the agility and repeated sprint exercise, participants were asked to describe onset of symptoms or side effects from caffeine ingestion; thereafter, participants consumed either a $\mathrm{CHO}$ solution containing $0.8 \mathrm{~g} \cdot \mathrm{kg}^{-1}$ body mass dextrose (Roquette, France) with $500 \mathrm{ml}$ of orange-flavored water or a placebo consisting of lowcalorie artificial sweetener (Prinsen BV, Helmond, The Netherlands) with $500 \mathrm{ml}$ of flavored water, and then participants consumed $300-500 \mathrm{ml}$ water throughout the testing. The appearance and taste of solutions were similar among treatments.

\section{Agility T-test (AT-test)}

The AT-test, referred to a previous study [38], was performed before and after the RSE. This protocol has been used to assess the agility of athletes participating in team-sport exercise $[40,41]$. It is a highly reliable measure of leg speed, leg power, and agility [38]. The agility test requires participants to run forward, lateral, and backward, as quickly as possible, and the total distance is 40 yard $(36.56 \mathrm{~m})$. Each trial was timed from start to completion by using an electronic timing system (SmartSpeed, Fusion Sport, Australia). Speed decrement of the AT-test was calculated based on a previous study [42]. The intra-class correlation coefficient (ICC, 0.87-0.98) and the coefficient of variance (CV, 4.3\%-4.6\%), which was calculated from the data between familiarization trial and first bout of AT-test in PLA + PLA trial, was good for AT-test. 


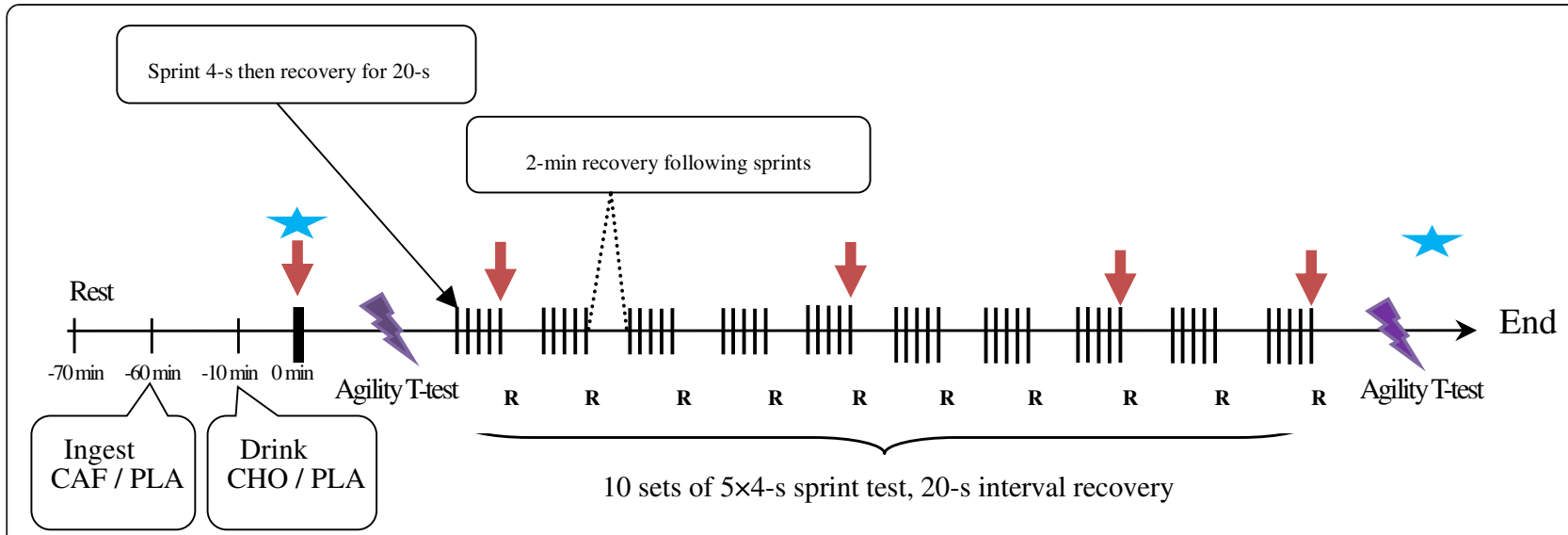

Figure 1 Schematic diagram of the 10 sets of $5 \times 4-s$ repeated sprint cycling test. $\downarrow$ : blood lactate and glucose. CAF: caffeine trial; PLA: placebo trial; CHO: carbohydrate trial. Asterisk: cortisol and testosterone. Lightning: agility T-test. R: rating of perceived exertion.

\section{Repeated sprint test}

Participants were weighed to determine the accurate load for the RSE, which was performed on a cycle ergometer (Avantronic Cyclus II, h/p $\operatorname{Cosmos}^{\oplus}$, Germany). The predetermined resistance was calculated according to body mass by using the following equation, produced by internal software: $0.7 \times$ body mass in $\mathrm{kg} /$ 0.173 . Then, participants performed a standardized warm up followed by the first $\mathrm{T}$ test. A brief unloaded sprint allowed participants to prepare for the subsequent RSE. Participants were required to stay seated on the cycle ergometer for the entire duration of the RSE to limit the recruitment of other muscle groups. During each sprint, participants were encouraged to cycle maximally for each 4-s bout and pedal as fast as possible against the given load. The protocol for the RSE consisted of ten sets of repeated sprints with 2 -min recovery at 50 watts at a self-selected speed (Figure 1). Each set was composed of $5 \times 4$-s sprints with a 20 -s active recovery $(60-70 \mathrm{rpm}, 50$ watts) performed between each sprint. This test was used in a previous study [16] and is designed to activate glycolysis and maximize PCr degradation [2,4]. They were informed at the end of the recovery phase at least 5-s prior to the beginning of the next sprint. Participants were given consistent verbal encouragement during each sprint, but no performance information was provided. The power output data were recorded during each sprint using the cycle ergometer software. After completing the protocol, all data were then transferred to a personal computer to calculate the peak power, mean power, total work, and sprint decrement (equation 1 ) as used in previous studies [3,42]. The ICC and CV for peak power during RSE were 0.86 - 0.99 and 5.6\% $6.4 \%$, respectively.

$$
S_{\text {decrement }}(\%)=\left\{1-\frac{(\mathrm{S} 1+\mathrm{S} 2+\mathrm{S} 3+\ldots+\text { Sfinal })}{\text { Sbest } \times \text { number of sprints }}\right\} \times 100
$$

\section{Blood analysis}

Blood samples $(5 \mathrm{~mL})$ were drawn with an indwelling venous cannula following treatment ingestion and immediately after exercise testing. This sample was placed in a tube and centrifuged at $3000 \mathrm{rpm}$ for $15-\mathrm{min}$. The resultant serum was stored at $-80^{\circ} \mathrm{C}$ for subsequent analysis of concentrations of cortisol and testosterone using radioimmunoassay (Wizard ${ }^{2}$ Automatic Gamma Counter, PerKin-Elmer Corp, USA), with a CV of less than $5 \%$ according to LEZEN reference laboratory (Taipei, Taiwan). In addition, a $20 \mu \mathrm{l}$ blood sample for analyzing blood glucose and lactate concentrations was collected from the earlobe immediately before RSE exercise (i.e. pre-test, which means the time point at $10 \mathrm{~min}$ after drinking $\mathrm{CHO} / \mathrm{PLA}$ beverage), and after sets 1,5 , 8 , and 10 of RSE exercise. To assess changes in blood glucose, a $10 \mu$ l earlobe blood sample was analyzed by Byer analyzer (Ascencia Breeze, Bayer HealthCare LLC, USA), and the remaining blood sample was used to obtain blood lactate concentration using methods described previously [16].

\section{Statistical analyses}

Data are reported as mean \pm standard deviation and were analyzed with SPSS for Windows (version 17.0, SPSS, Inc., Chicago IL, USA). Dependent variables (peak power, mean power, total work, and RPE) were analyzed using a ten (numbers of set) by four (treatment: CAF + $\mathrm{PLA}, \mathrm{CAF}+\mathrm{CHO}, \mathrm{PLA}+\mathrm{CHO}$, and PLA + PLA), twoway repeated-measures analysis of variance (ANOVA). 
Changes in concentration of lactate, glucose, cortisol, and testosterone as well as agility performance between treatments and over time were also analyzed with two-way repeated-measures ANOVA. One-way ANOVA was performed to study differences in performance decrement of AT-test and RSE between treatments. To minimize the violation of the assumption of homogeneity of variance, the Greenhouse-Geisser correction was used when sphericity was violated. When differences were identified by ANOVA, the Bonferroni adjustment was used to ascertain where the differences lay. Statistical significance was set at a $p$ value of $\leq .05$ for all analyses. The ICC and CV were computed from the data between familiarization and PLA + PLA trials to determine the test-retest reliability of the RSE and AT-test. Effect size was expressed as partial eta squared $\left(\eta^{2}\right)$. According to Portney et al. [43] , the magnitude of difference in key dependent variables is expressed as the $\eta^{2}$ using the following criteria: small $\eta^{2}=.01$, medium $\eta^{2}=.06$, large $\eta^{2}=.14$.

\section{Results}

\section{Repeated sprint ability}

\section{Peak power}

There was a significant interaction for peak power $(F=$ $\left.1.89, \eta^{2}=0.16, p<.01\right)$. Figure $2 \mathrm{~A}$ shows a significant difference in peak power output between PLA $+\mathrm{CHO}$ and CAF + PLA $(p<.05)$. Additionally, there was a significant difference in peak power across bouts among all treatments, as it declined across bouts. A main treatment effect was observed in Set $6\left(F=5.02, \eta^{2}=0.33, p<.01\right)$; post hoc analyses revealed there was a trend for greater peak power $(+3.8 \%)$ in PLA + CHO than PLA + PLA $(p=.08)$ and in $\mathrm{CAF}+\mathrm{CHO}$ than $\mathrm{CAF}+\mathrm{PLA}(+5.3 \%)(p=.08)$, respectively; however, this difference was non-significant.

\section{Mean power}

Figure $2 \mathrm{~B}$ summarizes changes in mean power during the RSE for each treatment. There was a significant treatment $\times$ time interaction for mean power $\left(F=1.64, \eta^{2}=\right.$ $0.14, p<.05)$. In PLA $+\mathrm{CHO}$, mean power differed from PLA + PLA at set 6 of RSE $(p<.05)$, but no difference was observed between CAF + PLA, CAF + CHO, PLA + CHO, and PLA + PLA across all other sets $(p>.05)$. Mean power was higher in set 1 than subsequent sprint sets across all treatments $(p<.05)$.

\section{Total work}

There was a significant treatment $\times$ time interaction for total work $\left(F=1.64, \eta^{2}=0.03, p<.05\right)$. Compared with
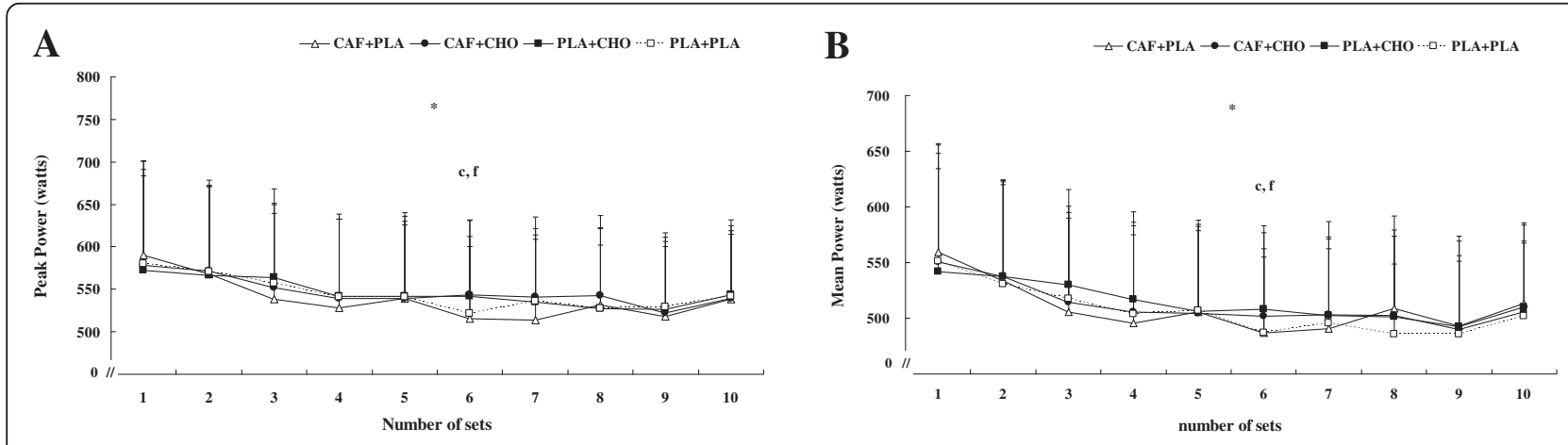

C

D $\square \mathrm{CAF}+\mathrm{PLA} \square \mathrm{CAF}+\mathrm{CHO}$ ØPLA+CHO $\square \mathrm{PLA}+\mathrm{PLA}$
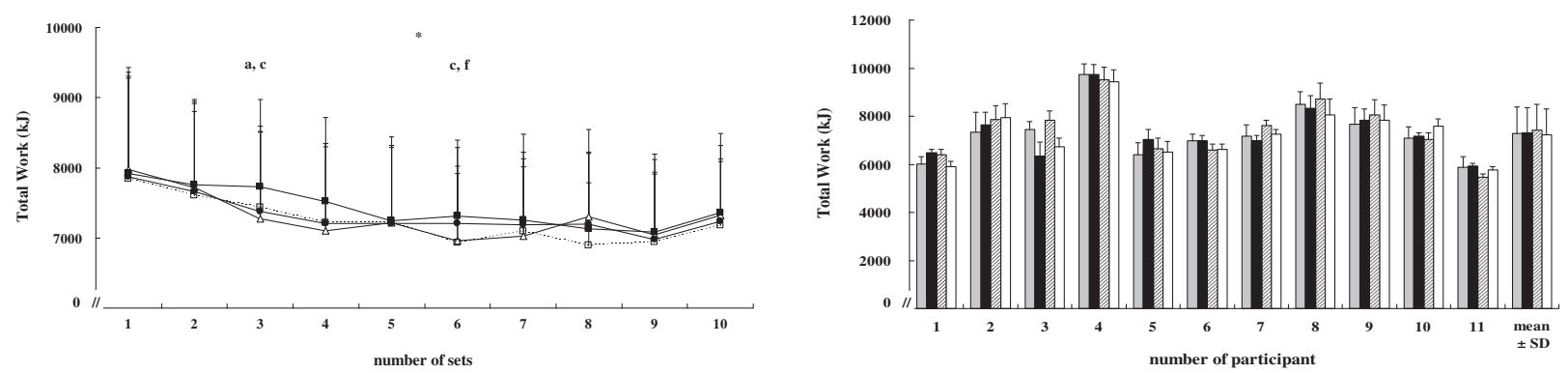

Figure 2 Changes in peak power (A), mean power (B), and total work (C) for each set of the repeated sprint test (10 sets of $5 \times 4$-s sprint with 20-s of rest intervals; 2 -min recovery after each set) for the conditions of caffeine + placebo (CAF + PLA), caffeine + carbohydrate $(\mathrm{CAF}+\mathrm{CHO})$, placebo + carbohydrate (PLA + CHO), and placebo + placebo (PLA + PLA). Individual differences in total work (D) for each condition throughout the testing. ${ }^{*}=$ significant time effect $(p<.05)$. a = significant difference between CAF $+\mathrm{CHO}$ and PLA $+\mathrm{CHO}(p<.05)$. $c=$ significant difference between CAF + PLA and PLA $+\mathrm{CHO}(p<.05) . f=$ significant difference between PLA $+\mathrm{CHO}$ and PLA + PLA $(p<.05)$. Values are mean \pm standard deviation. 
the PLA + PLA condition, total work in set 6 of PLA + $\mathrm{CHO}$ was significantly increased by $5.2 \%\left(F=3.20, \eta^{2}=\right.$ $0.24, p<.05)$ and greater by $4.1 \%\left(F=3.26, \eta^{2}=0.25\right.$, $p<.05)$ versus CAF + PLA during RSE; however, total work with $\mathrm{CAF}+\mathrm{CHO}$ did not differ from CAF + PLA or PLA + PLA in any of the other sets $(p>.05)$ (Figure 2C). Total work declined across sets in all treatments $(p<.01)$. Individual responses in total work are shown in Figure 2D. Most participants expressed minimal changes in work, although subject 3 revealed lower performance after CAF + $\mathrm{CHO}$ supplementation.

\section{RSE decrement, $H R$, and RPE}

Sprint decrement in total work was not significantly different between CAF + PLA $(18.5 \pm 5.5 \%), \quad \mathrm{CAF}+\mathrm{CHO}$ $(15.5 \pm 4.6 \%), \quad \mathrm{PLA}+\mathrm{CHO}(16.2 \pm 4.3 \%)$, or PLA + PLA $(17.3 \pm 2.8 \%)\left(F=1.33, \eta^{2}=0.12, p>.05\right)$. As shown in Figure 3, average HR during each set of the RSE was significantly higher in $\mathrm{CAF}+\mathrm{CHO}$ compared with $\mathrm{CAF}+$ PLA, PLA + CHO, and PLA + PLA $\left(F=7.76, \eta^{2}=0.44\right.$, $p<.01)$. There was a significant change in HR across sets $\left(F=80.49, \quad \eta^{2}=0.89, \quad p<.01\right)$, as HR increased from values equal to $144.5 \pm 3.0$ beats $/ \mathrm{min}(95 \% \mathrm{CI}=137.9 \pm$ 151.1 beats $/ \mathrm{min}$ ) from set 1 to near $164.4 \pm 3$ beats $/ \mathrm{min}$ $(95 \% \mathrm{CI}=158.7 \pm 170.2 \mathrm{beats} / \mathrm{min})$ at set 10 . However, no interaction was revealed for heart rate $\left(F=0.97, \eta^{2}=\right.$ $0.09, p>.05)$. In addition, there was no significant treatment $\times$ time interaction for RPE during the RSE ( $F=$ $\left.1.55, \eta^{2}=0.13, p>.05\right)$, whereas, RPE significantly increased during RSE in all treatments $(p<.05)$ (Figure 4$)$.

\section{Blood lactate and glucose concentrations}

There was a main effect for time and treatment $(p<.01)$ as well as an interaction for blood lactate concentration during exercise $\left(F=2.57, \eta^{2}=0.20, p<.01\right)$. Post hoc analyses show that blood lactate concentrations in $\mathrm{CAF}+\mathrm{PLA}$ and $\mathrm{CAF}+\mathrm{CHO}$ conditions were significantly higher than those in PLA $+\mathrm{CHO}$ and PLA + PLA conditions for Sets 5, 8, and 10 throughout the RSE $(p<.05$; Figure 5A). Blood lactate concentration increased from Set 1 to the last Set and was significantly higher than pretest $(p<.01)$ in all conditions.

There was an interaction for blood glucose concentration $\left(F=7.53, \eta^{2}=0.43, p<.01\right)$ as well as a main effect for treatment and time during exercise. Post hoc for treatment shows blood glucose was significantly higher in PLA + $\mathrm{CHO}$ compared with other treatments at pre-test and Set 1 during RSE, but caffeine ingestion combined with carbohydrate or placebo significantly increased glucose levels during subsequent RSE (Figure 5B). In addition, post hoc analyses show that blood glucose concentration was significantly higher at Set 1 compared to pre-test in CAF + $\mathrm{CHO}(p<.01)$, and higher blood glucose at Set 1 versus Set 5 in PLA + CHO $(p<.05)$. In addition, blood glucose concentration remained stable throughout RSE with CAF + PLA and PLA + PLA ingestion $(p>.05)$.

\section{Serum cortisol and testosterone concentrations}

No significant interaction was observed for serum cortisol $\left(F=0.34, \eta^{2}=0.33, p=.79\right)$ or testosterone $(F=$ $\left.0.31, \eta^{2}=0.03, p=.59\right)$, and there was no treatment effect for serum cortisol $\left(F=0.86, \eta^{2}=0.08, p=.48\right)$ or testosterone $\left(F=3.60, \quad \eta^{2}=0.26, p=.09\right)$. However, post-exercise serum cortisol and testosterone concentrations were significantly higher than at pre-test in all treatments $(p<.05)$ (Figures 6A-B). Additionally, no significant treatment $\times$ time interaction $\left(F=0.29, \eta^{2}=0.03, p=.84\right)$ or treatment effect were observed in testosterone/cortisol ratio at pre-test (CAF + PLA vs. CAF $+\mathrm{CHO}$ vs. PLA + $\mathrm{CHO}$ vs. PLA + PLA; $2.04 \pm 0.83$ vs. $1.93 \pm 0.62$ vs. $2.12 \pm$

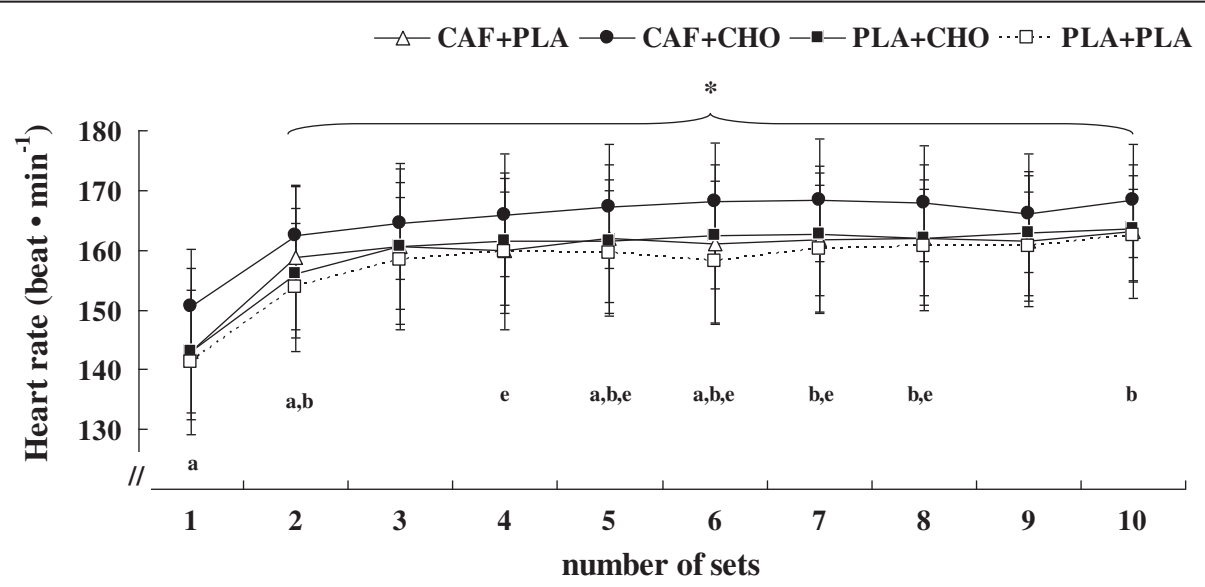

Figure 3 Change in heart rate during each set of the repeated sprint test for the conditions of caffeine + placebo (CAF + PLA), caffeine + carbohydrate (CAF + CHO), placebo + carbohydrate (PLA + CHO), and placebo + placebo (PLA + PLA). * $=$ significant time effect $(p<.01)$. $\mathrm{a}=$ significant difference between $\mathrm{CAF}+\mathrm{CHO}$ and $\mathrm{PLA}+\mathrm{CHO}(p<.05) \cdot \mathrm{b}=$ significant difference between $\mathrm{CAF}+\mathrm{CHO}$ and $\mathrm{PLA}+\mathrm{PLA}(p<.05)$. $\mathrm{e}=$ significant difference between CAF + PLA and PLA $+\mathrm{CHO}(p<.05)$. Values are mean \pm standard deviation. 


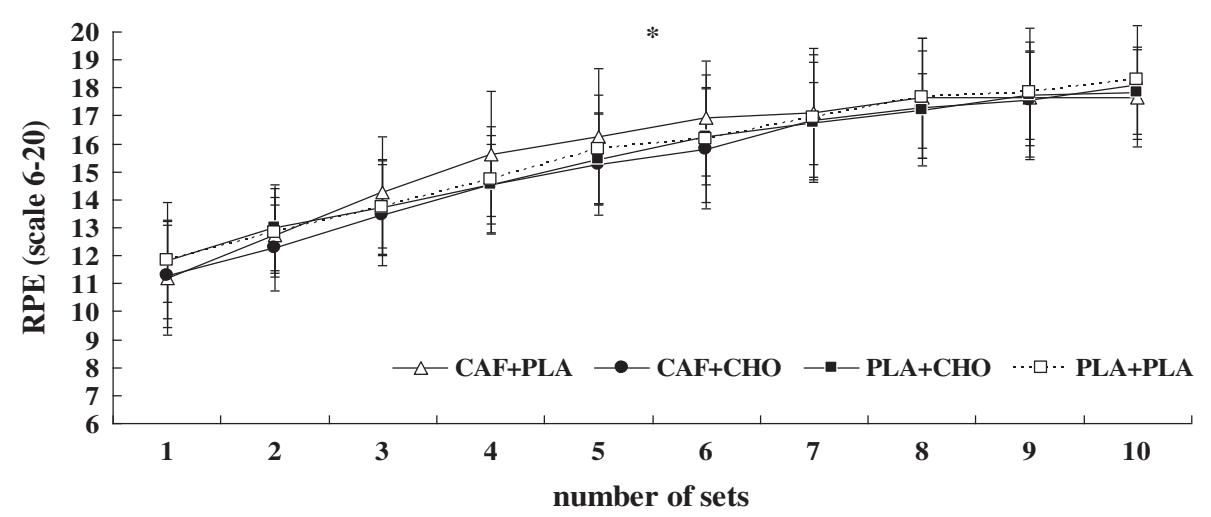

Figure 4 Change in rating of perceived exertion (RPE) during each set of the repeated sprint test for the conditions of caffeine + placebo $(\mathrm{CAF}+\mathrm{PLA})$, caffeine + carbohydrate $(\mathrm{CAF}+\mathrm{CHO})$, placebo + carbohydrate (PLA + CHO), and placebo + placebo (PLA + PLA). ${ }^{*}=$ significant time effect $(p<.01)$. Post hoc analyses show no significant difference was observed between treatments in any of the other sets $(p>$.05). Values are mean \pm standard deviation.

0.59 vs. $2.24 \pm 1.20, p>.05)$ or at post-test (CAF + PLA vs. $\mathrm{CAF}+\mathrm{CHO}$ vs. $\mathrm{PLA}+\mathrm{CHO}$ vs. PLA $+\mathrm{PLA} ; 2.03 \pm 0.36$ vs. $1.90 \pm 0.82$ vs. $2.00 \pm 0.85$ vs. 1.91 vs. $0.76, p>.05)$.

\section{AT-test performance}

The results show that a significant agility performance interaction did not exist $\left(F=2.14, \eta^{2}=0.18, p>.05\right)$, as well no significant main effects for time or treatment (Figure 7). Speed decrement was not significantly different among conditions (CAF + PLA vs. $\mathrm{CAF}+\mathrm{CHO}$ vs. $\mathrm{PLA}+\mathrm{CHO}$ vs. PLA + PLA, $-3.06 \pm 5.90 \%$ vs. $-2.98 \pm 3.96 \%$ vs. $-0.14 \pm$ $2.98 \%$ vs. $\left.-1.39 \pm 4.46 \% ; \quad F=2.14, \quad \eta^{2}=0.18, p>.05\right)$. However, agility performance in the PLA + CHO condition was relatively well-preserved compared to the other treatments.

\section{Side effects}

All participants filled out the side effect questionnaire to assess the possible adverse reaction 60-min after ingesting caffeine or placebo capsule. After ingestion of caffeine, one participant experienced anxiety and slight tremor, another experienced diarrhea, and a third experienced headache and flatulence. However, carbohydrate alone or placebo supplementation did not result in any uncomfortable issues for participants.

\section{Discussion}

To our knowledge, the present study is the first to examine the effects of caffeine $\left(6 \mathrm{mg} \cdot \mathrm{kg}^{-1}\right)$ combined with carbohydrate $\left(0.8 \mathrm{~g} \cdot \mathrm{kg}^{-1}\right)$ administration on repeated sprint performance $(10$ sets of $5 \times 4$-s sprint with 20 -s rest between each sprint) and agility in female athletes. The main findings indicate a significant increase in peak power, mean power, and total work with carbohydrate ingestion alone prior to commencing a repeated sprint exercise protocol. However, the sprint decrement and agility performance for the CAF $+\mathrm{PLA}, \mathrm{CAF}+\mathrm{CHO}$, $\mathrm{PLA}+\mathrm{CHO}$, and PLA + PLA conditions were not statistically different. Data also demonstrated that either coingestion of CAF and $\mathrm{CHO}$ or CAF alone significantly increased heart rate and blood lactate and glucose concentrations during later stages of the RSE, but did not alter testosterone or cortisol levels.

It has been documented that CAF's influence on anaerobic exercise capacity and agility may depend on the rest: work ratio [11]. Similar to the results of previous studies by Lee et al.[16], Paton et al. [17], and Stuart et al. [21], CAF alone did not improve repeated sprint ability. Thus, while further applied research certainly needs to be done, these results suggest that CAF provides negligible benefit to repeated sprint exercise with insufficient rest interval (work: rest ratio $=1: 5$ ).

Although a meta-analysis indicated that $\mathrm{CAF}+\mathrm{CHO}$ ingestion improved endurance performance when compared with $\mathrm{CHO}$ alone [44], the present study observed that $\mathrm{CAF}+\mathrm{CHO}$ ingestion does not benefit repeated sprint performance versus CAF + PLA, PLA $+\mathrm{CHO}$, or PLA + PLA. By contrast, the total work in PLA + CHO condition increased significantly at Set 3, compared to the $\mathrm{CAF}+\mathrm{CHO}$ and CAF + PLA conditions. Therefore, it is tempting to speculate that combining CAF with $\mathrm{CHO}$ supplementation has no additive effect on prolonged repeated sprint exercise, composed of 10 sets, $5 \times 4$-s sprints with 20 -s rest interval between each sprint. Furthermore, a performance-enhancing effect of $\mathrm{CHO}$ seemed to be negated by CAF when recreational male athletes performed 20-kilometer time trial [29]. This apparent discrepancy may be attributed to type (that is, prolonged repeated sprint exercises) and intensity (i.e. high-intensity and short recovery interval) of exercise performed in the present study, because previous study has indicated that anaerobic glycolysis supplies 


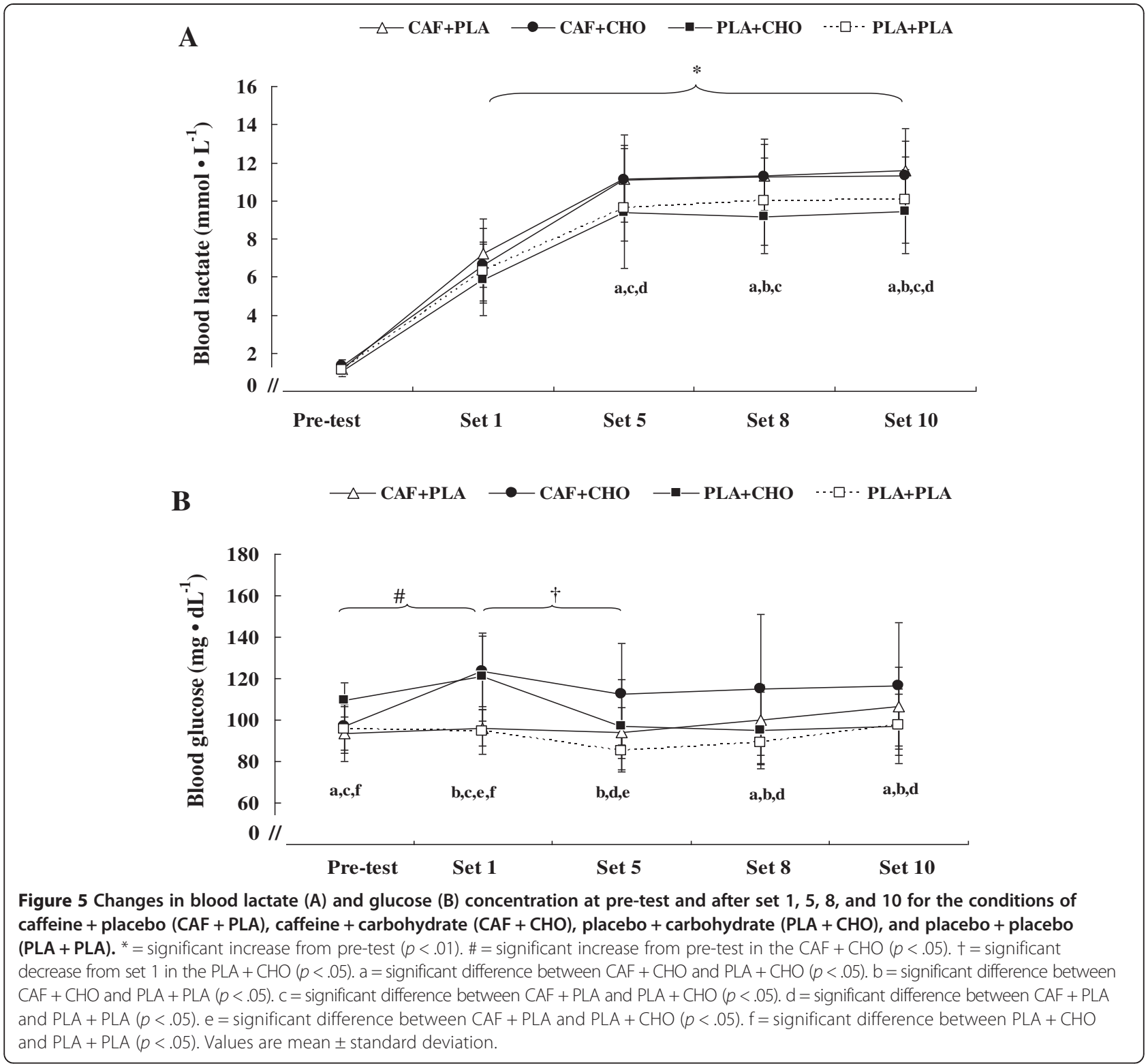

approximately $40 \%$ of the total energy during a single 6$\mathrm{s}$ sprint, with a progressive inhibition of glycolysis and decreased ATP production with subsequent sprints [4]. Data also show that blood lactate concentration was not significantly different at pre-test and Set 1 among treatments, but was significantly higher after CAF + PLA ingestion than PLA + CHO and PLA + PLA during later stages of the RSE. Lee et al. [16] demonstrated a significant increase in blood lactate concentrations and decreased fatigue resistance during the late stage of the RSE after CAF ingestion. By contrast, this study and others show that ingesting $\mathrm{CHO}$ does not affect the blood lactate response to sprint exercise $[45,46]$. This may reflect rapidly increasing anaerobic glycolysis, where lactate is produced when ingesting CAF [47]. CAF may impair performance for this type of exercise due to increased accumulation of by-products of anaerobic metabolism [48], a deficiency in the phosphagen system [4], and blocking CNS adenosine receptors [49] or activating $\mathrm{Na}^{+} / \mathrm{K}^{+}$ATPase [15]. Nevertheless, studies focused on the exact mechanism related with the effects of caffeine on energy substrate or nervous system should be conducted in future.

The present study showed that repeated sprint performance was improved followed $\mathrm{CHO}$ ingestion rather than $\mathrm{CAF}+\mathrm{CHO}$ ingestion or CAF ingestion alone. $\mathrm{CHO}$ supplementation before team sport exercise has been demonstrated to significantly improve high-intensity intermittent sprint performance [6] in non-glycogen depleted subjects, which may be attributed to improved cerebral glucose uptake [9], greater CNS function [50], and motor control 

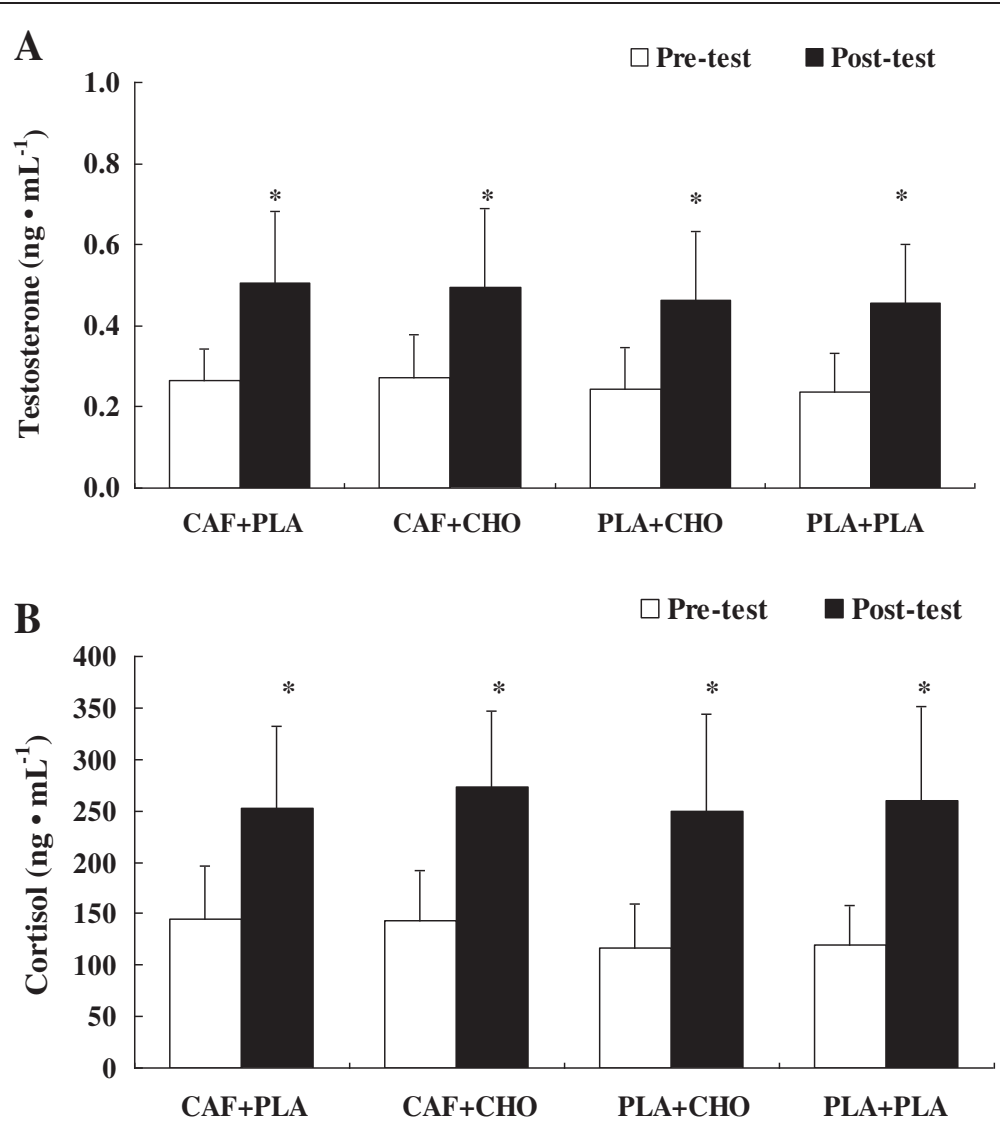

Figure 6 Changes in serum testosterone (A) and cortisol (B) concentrations in the conditions of caffeine + placebo (CAF + PLA), caffeine + carbohydrate $(\mathrm{CAF}+\mathrm{CHO})$, placebo + carbohydrate $(\mathrm{PLA}+\mathrm{CHO})$, and placebo + placebo $(\mathrm{PLA}+\mathrm{PLA}) .{ }^{*}=$ significant increase from pre-test $(p<.01)$. Values are mean \pm standard deviation.

[45]. Despite the intensity of RSE being higher than ISE [3], CHO ingestion affects the metabolic response to team sport exercise, with a significant increase in glucose concentration found throughout exercise [5,51]. The mechanisms driving this increased blood glucose concentration are largely unknown. Blood glucose concentration initially increases after ingesting $\mathrm{CAF}+\mathrm{CHO}$ or $\mathrm{PLA}+\mathrm{CHO}$ and it may be suppressed by endogenous glucose production [52]. The blood glucose levels gradually decreased in the $\mathrm{PLA}+\mathrm{CHO}$ trial during the RSE, suggesting that intense

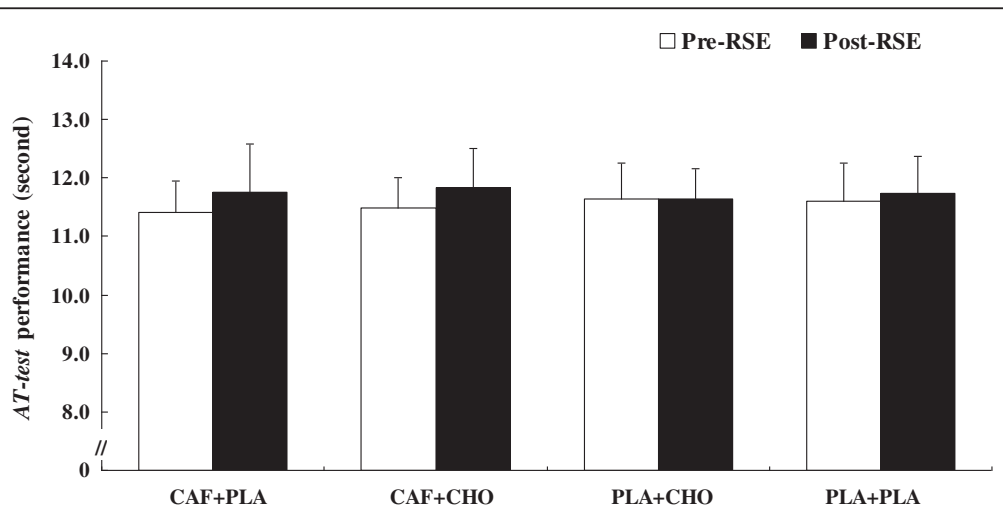

Figure 7 Changes in agility T-test (AT-test) performance for the conditions of caffeine + placebo (CAF + PLA), caffeine + carbohydrate $(\mathrm{CAF}+\mathrm{CHO})$, placebo + carbohydrate (PLA + CHO), and placebo + placebo (PLA + PLA). RSE: repeated sprint exercise. Values are mean \pm standard deviation. 
sprint exercise increases fuel requirements in working muscles and obligates more blood glucose to muscle cells during the RSE. By contrast, the $\mathrm{CAF}+\mathrm{CHO}$ exhibited higher blood glucose levels during the RSE, partly because caffeine is crucial for maintaining blood glucose concentration by enhancing glycolytic turnover [11].

Although the exact mechanisms of carbohydrate ingestion on exercise performance, especially for exercise duration less than 1 hour, are not well understood, two major explanations are commonly used to interpret the possible ergogenic effects of carbohydrate. Firstly, the general metabolic response to prolonged intermittent exercise with $\mathrm{CHO}$ administration is an increase in plasma glucose concentration and higher rates of glucose oxidation during the later exercise stage [9]. Secondly, the presence of carbohydrate in the mouth has been shown to stimulate the receptors in the oral cavity, thus activating specific areas of the brain associated with reward and the regulation of motor activity [27].

$\mathrm{CHO}$ ingestion may increase blood glucose concentrations, however, it should be noted that the improved performance in previous studies [45] might be attributed to the glycogen-depleted state prior to the intermittent sprint exercise. In this study, we asked participants to consume a standardized meal 2 hours before exercise test to mimic the real-life situation, e.g., fed athletes before competition, in each trial. The results indicate that ingestion of PLA + $\mathrm{CHO}$ provided a small but significant benefit on RSE performance in female athletes. Nevertheless, Colombani et al. [53] reported that $\mathrm{CHO}$ administration might not induce performance improvements in male athletes during exercise lasting less than 70-min in postprandial state.

The increases in blood glucose levels and repeated sprint performance induced by $\mathrm{CHO}$ ingestion may also involve the central governor. Gastric empty rate of a $\mathrm{CHO}$ drink could be slowed by the hypertonic drink [54] and high-intensity intermittent sprint [55]. Jeukendrup et al. [56] reported that $\mathrm{CHO}$ ingestion has no effects on exogenous glucose uptake and total $\mathrm{CHO}$ oxidation during short-term ( $\sim 1$ hour) high-intensity cycling exercise. Although the mechanism responsible for the improvement in short-term $(<1$ hour) high-intensity exercise performance with $\mathrm{CHO}$ ingestion is not well known, some studies suggest that the $\mathrm{CHO}$ mouth rinsing stimulates the receptors in mouth, which modulate central pathways associated with motivation and improve the perceptions of effort $[8,27]$. Total RPE scores in $\mathrm{CAF}+\mathrm{CHO}$ and PLA $+\mathrm{CHO}$ were slightly with non-significantly lower than those in other treatments (CAF + PLA vs. CAF + $\mathrm{CHO}$ vs. PLA $+\mathrm{CHO}$ vs. PLA + PLA, $157 \pm 18$ vs. $152 \pm$ 16 vs. $154 \pm 13$ vs. $156 \pm 17, p>.05)$. More than half of participants in $\mathrm{CAF}+\mathrm{CHO}(7 / 11,64 \%)$ and PLA + CHO (6/11, 55\%) had lesser total RPE scores while comparing with PLA + PLA condition. Therefore, our study might provide some supports for the attenuation of perceptions of effort resulted from the $\mathrm{CHO}$ supplementation. In addition, our results in RSE performance are partially in agreement with Beaven et al. [27], who found the CAF and (or) $\mathrm{CHO}$ mouth rinse can rapidly enhance initial cycle sprint power production; however, recent study [57] reported that the $\mathrm{CHO}$ mouth rinse could not improve performance during simulated team-sport exercise (i.e., Loughborough Intermittent Shuttle Test). Therefore, further studies are needed to clarify the existence of $\mathrm{CHO}$ receptors in oral cavity and their effect on RSE performance.

Testosterone and cortisol concentrations have been reported to increase in response to high-intensity activity in humans [58], and with CAF [33] or CHO ingestion [36], respectively. Data from this study show that ingesting $\mathrm{CAF}$ or $\mathrm{CHO}$ does not alter the circulating levels of testosterone or cortisol, but these levels increased distinctly after the AT- test in all four conditions (Figure 6). One study examined alterations in salivary testosterone and cortisol in nine male cyclists completing repeated sprint test ( 4 sets of $5 \times 30$-s sprints, interspersed with 30 -s recovery intervals) following caffeinated chewing gum ingestion [18]. Results showed that cortisol was increased by $12 \%$ and testosterone decreased by $21 \%$ compared to placebo condition, although testosterone and cortisol levels were not significantly different between caffeine and placebo trials $(p>.05)$. Testosterone concentration is related to exercise intensity and increases with greater force production, and testosterone/cortisol ratio is associated with the anabolic or catabolic status of skeletal muscle during exercise [58]. Cortisol exhibits catabolic functions and increases in volume with repetitive high-intensity exercise, and the rest interval length also affects the acute cortisol response [58]. However, Beaven et al. [34] indicated that the anabolic effect of the increase in testosterone concentrations after CAF ingestion may be counteracted by the opposing catabolic effects of the increase in cortisol concentrations. Walker et al. [35] reported that ingesting $\mathrm{CHO}$ produced lower plasma cortisol concentrations than CAF and PLA after cycling for $2 \mathrm{~h}$ at $65 \% \mathrm{VO}_{2 \max }$, but the type of exercise was different than that used in this study. In addition, plasma cortisol concentrations (approximately $145-193 \mathrm{ng} \cdot \mathrm{dL}^{-1}$ ) induced by the prolonged submaximal exercise in the study of Walker et al. [35] are obviously lower than those in our study. Pre and post-intermittent exercise did not produce significantly different salivary cortisol concentrations after $\mathrm{CHO}$ beverage ingestion [59]. According to the results from the current investigation, adding $\mathrm{CHO}$ to a solution and ingesting a CAF capsule does not affect hormone variables. This is probably because the intensity of the RSE exerts a strong influence on hormones without ergogenic aids. Changes in these hormones during RSE after ingesting $\mathrm{CAF}$ and $\mathrm{CHO}$ require further investigation. 


\section{Conclusions}

The data demonstrate that ingesting $\mathrm{CAF}$ and $\mathrm{CHO}$ or only CAF does not increase peak or mean power, or total work during RSE, or improve agility, compared to ingesting PLA + PLA. In contrast to $\mathrm{CAF}+\mathrm{CHO}, \mathrm{CAF}+$ $\mathrm{PLA}$, and PLA + PLA conditions, ingesting PLA $+\mathrm{CHO}$ increased sprint performance during 10 sets of $5 \times 4$-s sprints, with a 20-s rest interval between each sprint (2min rest between each set). Ingesting PLA $+\mathrm{CHO}$ did not alter RPE, agility performance, or hormone profiles. The results suggest that in female athletes, ingesting $\mathrm{CHO}$ without $\mathrm{CAF}$ before exercise may increase repeated sprint performance.

\section{Abbreviations}

CAF: Caffeine; CHO: Carbohydrate; Cl: Confidence interval; CNS: Central nervous system; CV: Coefficient of variation; HR: Heart rate; ICC: Intra-class correlation coefficient; ISE: Intermittent sprint exercise; PLA: Placebo; RPE: Rating of perceived exertion; RSE: Repeated sprint exercise.

\section{Competing interests}

The authors declare that they have no competing of interest.

\section{Authors' contributions}

CLL and CFC developed the study design, data collection, statistical analysis, and all sport drink tested. TA helped draft the manuscript. JCL was in charge of participant recruitment and management. HWH contributed to the data collection and analysis. WDC provided consultation. All authors contributed to drafting of the manuscript. All authors have read and approved the final manuscript.

\section{Acknowledgements}

We would like to thank all participants and research assistants for their effort in the study. This work was partly supported by a research grant from the Ministry of Science and Technology, Taiwan (NSC 101-2410-H-110-085). This work was also particularly supported by "Aim for the Top University Plan" of National Taiwan Normal University, National Sun Yat-sen University, and the Ministry of Education, Taiwan.

\section{Author details}

${ }^{1}$ Physical Education Section of General Education, National Sun Yat-sen University, Kaohsiung, Taiwan. ${ }^{2}$ Department of Athletic Performance, National Taiwan Normal University, Taipei, Taiwan. ${ }^{3}$ Department of Kinesiology, California State University-San Marcos, San Marcos, CA, USA. ${ }^{4}$ Department of Physical Education, National Taiwan Normal University, Taipei, Taiwan.

${ }^{5}$ Department of Sports Medicine, China Medical University, Taichung, Taiwan.

Received: 14 October 2013 Accepted: 17 April 2014

Published: 1 May 2014

\section{References}

1. Coutts AJ, Reaburn PR: Time and motion analysis of the AFL field umpire. Australian football league. J Sci Med Sport 2000, 3:132-139.

2. Spencer M, Bishop D, Dawson B, Goodman C: Physiological and metabolic responses of repeated-sprint activities:specific to field-based team sports. Sports Med 2005, 35:1025-1044.

3. Girard O, Mendez-Villanueva A, Bishop D: Repeated-sprint ability - part I: factors contributing to fatigue. Sports Med 2011, 41:673-694.

4. Gaitanos GC, Williams C, Boobis LH, Brooks S: Human muscle metabolism during intermittent maximal exercise. J Appl Physiol 1993, 75:712-719.

5. Welsh RS, Davis JM, Burke JR, Williams HG: Carbohydrates and physical/ mental performance during intermittent exercise to fatigue. Med Sci Sports Exerc 2002, 34:723-731.

6. Davison GW, McClean C, Brown J, Madigan S, Gamble D, Trinick T, Duly E: The effects of ingesting a carbohydrate-electrolyte beverage 15 minutes prior to high-intensity exercise performance. Res Sports Med 2008, 16:155-166
7. Phillips SM, Turner AP, Sanderson MF, Sproule J: Beverage carbohydrate concentration influences the intermittent endurance capacity of adolescent team games players during prolonged intermittent running. Eur J Appl Physiol 2012, 112:1107-1116.

8. Carter JM, Jeukendrup AE, Jones DA: The effect of carbohydrate mouth rinse on 1-h cycle time trial performance. Med Sci Sports Exerc 2004, 36:2107-2111.

9. Phillips SM, Sproule J, Turner AP: Carbohydrate ingestion during team games exercise: current knowledge and areas for future investigation. Sports Med 2011, 41:559-585.

10. Burke LM, Hawley JA, Wong SH, Jeukendrup AE: Carbohydrates for training and competition. J Sports Sci 2011, 29(Suppl 1):S17-27.

11. Davis JK, Green JM: Caffeine and anaerobic performance: ergogenic value and mechanisms of action. Sports Med 2009, 39:813-832.

12. Glaister M, Howatson G, Abraham CS, Lockey RA, Goodwin JE, Foley P, Mclnnes G: Caffeine supplementation and multiple sprint running performance. Med Sci Sports Exerc 2008, 40:1835-1840.

13. Schneiker KT, Bishop D, Dawson B, Hackett LP: Effects of caffeine on prolonged intermittent-sprint ability in team-sport athletes. Med $\mathrm{SCl}$ Sports Exerc 2006, 38:578-585.

14. Duvnjak-Zaknich DM, Dawson BT, Wallman KE, Henry G: Effect of caffeine on reactive agility time when fresh and fatigued. Med Sci Sports Exerc 2011, 43:1523-1530.

15. Sökmen B, Armstrong LE, Kraemer WJ, Casa DJ, Dias JC, Judelson DA, Maresh CM: Caffeine use in sports: considerations for the athlete. J Strength Cond Res 2008, 2:978-986.

16. Lee CL, Cheng CF, Lin JC, Huang HW: Caffeine's effect on intermittent sprint cycling performance with different rest intervals. Eur J App/ Physiol 2012, 112:2107-2116.

17. Paton $C D$, Hopkins WG, Vollebregt L: Little effect of caffeine ingestion on repeated sprints in team-sport athletes. Med Sci Sports Exerc 2001, 33:822-825

18. Paton CD, Lowe $\mathrm{T}$, Irvine $\mathrm{A}$ : Caffeinated chewing gum increases repeated sprint performance and augments increases in testosterone in competitive cyclists. Eur J Appl Physiol 2010, 110:1243-1250.

19. Lorino AJ, Lloyd LK, Crixell SH, Walker JL: The effects of caffeine on athletic agility. J Strength Cond Res 2006, 20:851-854.

20. Foskett A, Ali A, Gant N: Caffeine enhances cognitive function and skill performance during simulated soccer activity. Int I Sport Nutr Exerc Metab 2009, 19:410-423.

21. Stuart GR, Hopkins WG, Cook C, Cairns SP: Multiple effects of caffeine on simulated high-intensity team-sport performance. Med Sci Sports Exerc 2005, 37:1998-2005.

22. Yeo SE, Jentjens RL, Wallis GA, Jeukendrup AE: Caffeine increases exogenous carbohydrate oxidation during exercise. J Appl Physiol 2005, 99:844-850.

23. Van Nieuwenhoven MA, Brummer RM, Brouns F: Gastrointestinal function during exercise: comparison of water, sports drink, and sports drink with caffeine. J Appl Physiol 2000, 89:1079-1085.

24. Hulston CJ, Jeukendrup AE: Substrate metabolism and exercise performance with caffeine and carbohydrate intake. Med Sci Sports Exerc 2008, 40:2096-2104.

25. Roberts SP, Stokes KA, Trewartha G, Doyle J, Hogben P, Thompson D: Effects of carbohydrate and caffeine ingestion on performance during a rugby union simulation protocol. J Sports Sci 2010, 28:833-842.

26. Gant N, Ali A, Foskett A: The influence of caffeine and carbohydrate coingestion on simulated soccer performance. Int I Sport Nutr Exerc Metab 2010, 20:191-197.

27. Beaven CM, Maulder P, Pooley A, Kilduff L, Cook C: Effects of caffeine and carbohydrate mouth rinses on repeated sprint performance. Appl Physiol Nutr Metab 2013, 38:633-637.

28. Cooper R, Naclerio F, Allgrove J, Larumbe-Zabala E: Effects of a carbohydrate and caffeine gel on intermittent sprint performance in recreationally trained males. Eur J Sport Sci 2013. published ahead of print.

29. Slivka D, Hailes W, Cuddy J, Ruby B: Caffeine and carbohydrate supplementation during exercise when in negative energy balance: effects on performance, metabolism, and salivary cortisol. Appl Physiol Nutr Metab 2008, 33:1079-1085.

30. Hunter AM, St Clair Gibson A, Collins M, Lambert M, Noakes TD: Caffeine ingestion does not alter performance during a 100-km cycling time-trial performance. Int J Sport Nutr Exerc Metab 2002, 12:438-452. 
31. Astorino TA, Matera AJ, Basinger J, Evans M, Schurman T, Marquez R: Effects of red bull energy drink on repeated sprint performance in women athletes. Amino Acids 2012, 42:1803-1808.

32. Thomas NE, Leyshon A, Hughes MG, Jasper MA, Davies B, Graham MR, Bulloch JM, Baker JS: Concentrations of salivary testosterone, cortisol, and immunoglobulin A after supra-maximal exercise in female adolescents. J Sports Sci 2010, 28:1361-1368.

33. Lovallo WR, Whitsett TL, Al'Absi M, Sung BH, Vincent AS, Wilson MF: Caffeine stimulation of cortisol secretion across the waking hours in relation to caffeine intake levels. Psychosom Med 2005, 67:734-739.

34. Beaven CM, Hopkins WG, Hansen KT, Wood MR, Cronin JB, Lowe TE: Dose effect of caffeine on testosterone and cortisol responses to resistance exercise. Int J Sport Nutr Exerc Metab 2008, 18:131-141.

35. Walker GJ, Finlay O, Griffiths H, Sylvester J, Williams M, Bishop NC: Immunoendocrine response to cycling following ingestion of caffeine and carbohydrate. Med Sci Sports Exerc 2007, 39:1554-1560.

36. Lane AR, Duke JW, Hackney AC: Influence of dietary carbohydrate intake on the free testosterone: cortisol ratio responses to short-term intensive exercise training. Eur J Appl Physiol 2010, 108:1125-1131.

37. Nehlsen-Cannarella SL, Fagoaga OR, Nieman DC, Henson DA, Butterworth DE, Schmitt RL, Bailey EM, Warren BJ, Utter A, Davis JM: Carbohydrate and the cytokine response to $2.5 \mathrm{~h}$ of running. J App/ Physiol 1997, 82:1662-1667.

38. Pauole K, Madole K, Garhammer J, Lacourse M, Rozenek R: Reliability and validity of the T-test as a measure of agility, Leg power, and Leg speed in college-aged Men and women. J Strength Cond Res 2000, 14:443-450.

39. Borg G: Simple rating methods for estimation of perceived exertion. In Physical Work and Effort. Edited by Borg G. New York: Pergamon Press; 1975:39-46.

40. Delextrat A, Cohen D: Physiological testing of basketball players: toward a standard evaluation of anaerobic fitness. J Strength Cond Res 2008, 22:1066-1072

41. Hickey KC, Quatman CE, Myer GD, Ford KR, Brosky JA, Hewett TE: Methodological report: dynamic field tests used in an NFL combine setting to identify lower-extremity functional asymmetries. J Strength Cond Res 2009, 23:2500-2506.

42. Glaister M, Howatson G, Pattison JR, McInnes G: The reliability and validity of fatigue measures during multiple-sprint work: an issue revisited. J Strength Cond Res 2008, 22:1597-1601.

43. Portney LG, Watkins MP: Foundations of Clinical Research: Applications to Practice. 3rd edition. New Jersey: Pearson Education; 2009.

44. Conger SA, Warren GL, Hardy MA, Millard-Stafford ML: Does caffeine added to carbohydrate provide additional ergogenic benefit for endurance? Int J Sport Nutr Exerc Metab 2011, 21:71-84.

45. Ali A, Williams C, Nicholas CW, Foskett A: The influence of carbohydrateelectrolyte ingestion on soccer skill performance. Med Sci Sports Exerc 2007, 39:1969-1976.

46. Nicholas CW, Tsintzas K, Boobis L, Williams C: Carbohydrate-electrolyte ingestion during intermittent high-intensity running. Med Sci Sports Exerc 1999, 31:1280-1286

47. Tarnopolsky MA: Caffeine and creatine use in sport. Ann Nutr Metab 2010, 57(Suppl 2):1-8

48. Buchheit M, Cormie P, Abbiss CR, Ahmaidi S, Nosaka KK, Laursen PB: Muscle deoxygenation during repeated sprint running: Effect of active vs. passive recovery. Int J Sports Med 2009, 30:418-425.

49. Davis JM, Zhao Z, Stock HS, Mehl KA, Buggy J, Hand GA: Central nervous system effects of caffeine and adenosine on fatigue. Am J Physiol Regul Integr Comp Physiol 2003, 284:R399-404.

50. Winnick JJ, Davis JM, Welsh RS, Carmichael MD, Murphy EA, Blackmon JA: Carbohydrate feedings during team sport exercise preserve physical and CNS function. Med Sci Sports Exerc 2005, 37:306-315.

51. Foskett A, Williams C, Boobis L, Tsintzas K: Carbohydrate availability and muscle energy metabolism during intermittent running. Med Sci Sports Exerc 2008, 40:96-103.

52. Jeukendrup AE, Wagenmakers AJ, Stegen JH, Gijsen AP, Brouns F, Saris WH: Carbohydrate ingestion can completely suppress endogenous glucose production during exercise. Am J Physiol 1999, 276:E672-683.

53. Colombani PC, Mannhart C, Mettler S: Carbohydrates and exercise performance in non-fasted athletes: a systematic review of studies mimicking real-life. Nutr J 2013, 12:16.
54. Clayton DJ, Evans GH, James LJ: Effect of drink carbohydrate content on post-exercise gastric emptying, rehydration and the calculation of net fluid balance. Int J Sport Nutr Exerc Metab 2014, 24:79-89.

55. Leiper JB, Broad NP, Maughan RJ: Effect of intermittent high-intensity exercise on gastric emptying in man. Med Sci Sports Exerc 2001, 33:1270-1278.

56. Jeukendrup A, Brouns F, Wagenmakers AJ, Saris WH: Carbohydrate-electrolyte feedings improve $1 \mathrm{~h}$ time trial cycling performance. Int J Sports Med 1997, 18:125-129.

57. Dorling $J$, Earnest CP: Effect of carbohydrate mouth rinsing on multiple sprint performance. J Int Soc Sports Nutr 2013, 10:41.

58. Kraemer WJ, Ratamess NA: Hormonal responses and adaptations to resistance exercise and training. Sports Med 2005, 35:339-361.

59. Sari-Sarraf V, Doran DA, Clarke ND, Atkinson G, Reilly T: Effects of carbohydrate beverage ingestion on the salivary IgA response to intermittent exercise in the heat. Int J Sports Med 2011, 32:659-665.

doi:10.1186/1550-2783-11-17

Cite this article as: Lee et al:: Effects of carbohydrate combined with caffeine on repeated sprint cycling and agility performance in female athletes. Journal of the International Society of Sports Nutrition 2014 11:17.

\section{Submit your next manuscript to BioMed Central and take full advantage of:}

- Convenient online submission

- Thorough peer review

- No space constraints or color figure charges

- Immediate publication on acceptance

- Inclusion in PubMed, CAS, Scopus and Google Scholar

- Research which is freely available for redistribution 